\title{
Review
}

\section{Environmental and functional limits to muscular exercise and body size in marine invertebrate athletes ${ }^{\text {is }}$}

\author{
Hans O. Pörtner* \\ Alfred-Wegener-Institut für Polar- und Meeresforschung, Ökophysiologie, Postfach 1201 61, D-27515 Bremerhaven, FRG
}

Received 11 June 2001; accepted 7 November 2001

\begin{abstract}
Many similarities exist between the key characteristics of muscular metabolism in marine invertebrates and those found in vertebrate striated muscle, even though there are important phosphagens and glycolytic end products that differ between groups. Lifestyles and modes of locomotion also vary extremely among invertebrates thereby shaping the pattern of exercise metabolism. In accordance with the limited availability of integrated ecological and physiological information the present paper reports recent progress in the exercise physiology of cephalopods, which are characterized by high rates of aerobic and anaerobic energy turnover during high velocity hunts or escapes in their pelagic environment, and a sipunculid worm, which mostly uses anaerobic resources during extended marathon-like digging excursions in the hypoxic marine sediment. Particular attention is paid to how lifestyle and oxygen availability in various marine environments shapes the use and rates of aerobic and anaerobic metabolism and acidosis as they depend on activity levels and energy saving strategies. Whereas aerobic scope and, accordingly, use of ambient oxygen by blood oxygen transport and skin respiration is maximized in some squids, aerobic scope is very small in the worm and anaerobic metabolism readily used upon muscular activity. Until recently, it was widely accepted that the glycolytic end product octopine, produced in the musculature of these invertebrates, acted as a weak acid and so did not compromise acid-base balance. However, it has now been demonstrated that octopine does cause acidosis. Concomitant study of tissue energy and acid-base status allows to evaluate the contribution of glycolysis, $\mathrm{pH}$ and free ADP accumulation to the use of the phosphagen and to the delayed drop in the Gibb's free energy change of ATP hydrolysis. The analysis reveals species specific capacities of these mechanisms to support exercise beyond the anaerobic threshold. During high intensity anaerobic exercise observed in squid, the levels of ATP free energy change finally fall to critical minimum levels contributing to fatigue. Maintenance of sufficiently high energy levels is found at low but extended rates of anaerobic metabolism as observed in the long term digging sipunculid worm. The greatest aerobic and anaerobic performance levels are seen in squid inhabiting the open ocean and appear to be made possible by the uniform and stable physicochemical parameters (esp. high $\mathrm{O}_{2}$ and low $\mathrm{CO}_{2}$ levels) that characterize such an environment. It is suggested that at least some squid operate at their functional and environmental limits. In extremely different environments, both the worm and the squids display a tradeoff between oxygen availability, temperature, performance level and also, body size.
\end{abstract}

(C) 2002 Elsevier Science Inc. All rights reserved.

Keywords: Anaerobic vs. aerobic metabolism; Aerobic scope; Body size; Cephalopod; Cold adaptation; Critical velocity; Deep sea; Muscle energetics; Giant squid; Gibb's free energy of ATP hydrolysis; Intracellular pH; Marine invertebrate; Muscle metabolism; Octopine; Oxygen availability; Performance; Phosphagen; Squid; Sipunculid worm; Temperature

\footnotetext{
th This paper was presented in the session, 'Physiology and Biochemistry of Exercise', at the Society for Experimental Biology, April 2-6, 2001, Canterbury, UK.

*Tel.: +49-471-4831-1307; fax: +49-471-4831-1149.

E-mail address: hpoertner@awi-bremerhaven.de (H.O. Pörtner).
} 


\section{Introduction: muscular activity and mode of life}

There is tremendous diversity in the lifestyles and modes of locomotion among marine invertebrates, thereby shaping the pattern of muscular metabolism. Neglecting those forms that float in the pelagic owing to neutral buoyancy mechanisms modes of locomotion or muscular activity range from swimming, walking, digging in the sediment or just holding tight (e.g. by means of catch muscles used for valve closures) with decreasing levels of energy turnover in that order. Athletes in the sense that animals regularly and extensively use maximal levels of muscular performance as part of their lifestyle can be found in several groups, however, the characteristics of muscular activity in the context of environmental and lifestyle constraints have only been studied in very few cases. The present review tries to evaluate these relationships in four examples, where such analysis appears possible. Three of those examples are different squid species and one is a sipunculid worm. These four species live in various environments, the three squid in different parts of the pelagic, ranging from inshore and coastal waters to the open ocean, whereas the sipunculid lives in preliminary burrows in the intertidal and subtidal zone and is characterized by extended digging excursions during feeding in the marine sediment. These contrasting environments are characterized by different degrees of stability of environmental factors, like oxygen and $\mathrm{CO}_{2}$ concentrations, salinity and temperature. A physiological approach allows to identify to what extent these environmental parameters represent limits to the levels of performance reached, as well as to other speciesspecific features like body size.

Whereas the sipunculid worm, Sipunculus nudus, is well adapted to life in the hypoxic marine sediment by means of low aerobic metabolic rate and oxyconformity on the one side and a moderate to high resistance to long term anaerobiosis on the other side (Pörtner et al., 1984b, 1985) squid display the highest rates of muscular energy turnover among invertebrates and are found in diverse marine environments ranging from the pelagic of shallow estuaries or shelf and open oceans to the dark and permanently cold deep sea including the polar oceans (for general reviews see Wells, 1994; Pörtner and Zielinski, 1998). They are the sole large invertebrates to compete successfully with marine vertebrates (fish and marine mammals) in that they have conquered the pelagic zone and occupy similar positions in ecosystems and food webs. Usually, squid living in shelf environments or in the illuminated upper water layers are muscular and not neutrally buoyant. Based on their extreme rates of aerobic metabolism they ensure their position in the pelagic ecosystem by displaying a level of activity which is comparable to, or even exceeds, that of similar sized fish. In contrast, deep sea and some polar squid have developed neutral buoyancy by accumulating ammonium salts in separate fluid filled chambers and, thereby, likely lead a less expensive life in deep or cold oceans.

The mode of locomotion differs extremely between the squid and the sipunculid worm. Performance in the worms, which reach between 10 and $80 \mathrm{~g}$ body weight depending on the grain size of the sediment (see below), can be studied by simply placing them on the sediment surface thereby eliciting digging excursions of various lengths. The worm operates as a hydraulic machine while penetrating the marine sandy sediment (Trueman and Foster-Smith, 1976). In a simplified picture major forces are exerted by the musculature (circular and longitudinal muscles) on the non-chambered coelomic fluid which is then used to repeatedly expel the introvert into the sediment where it forms an anker allowing the rest of the body to follow by contraction of the longitudinal muscles.

Performance levels and energy metabolism in squid have been studied in swim tunnel experiments (O'Dor et al., 1990; O'Dor and Webber, 1991), in greatest detail in the ommastrephid squid Illex illecebrosus and the loliginid squids Loligo pealei and, most recently Lolliguncula brevis (Webber and O'Dor, 1985; Pörtner et al., 1991, 1993, 1996; Finke et al., 1996). The majority of studies with I. illecebrosus or L. pealei have been carried out on specimens up to $50 \mathrm{~cm}$ in length and weighing between 300 and $600 \mathrm{~g}$, whereas investigations with Lolliguncula used animals of 6-35 g and 5-9 cm mantle length. I. illecebrosus, $L$. pealei, and $L$. brevis also differ in their choice of habitat and way of life. L. pealei, like many other loliginids, is more or less non-migratory and restricted to coastal waters. The brief squid, $L$. brevis lives in warmer water and even enters very shallow and brackish waters in the inshore environment. In contrast I. illecebrosus, like many 
Table 1

Comparison of basal metabolic rates $\left(\mathrm{mmolO}_{2} \mathrm{~kg}^{-1} \mathrm{~h}^{-1}\right)$ with active (i.e. maximum) metabolic rates at critical swimming velocities (modified after Pörtner and Zielinski, 1998)

\begin{tabular}{|c|c|c|c|c|c|}
\hline & $\begin{array}{l}\text { Oncorhynchus } \\
\text { nerka }\end{array}$ & $\begin{array}{l}\text { Scomber } \\
\text { scombrus }\end{array}$ & $\begin{array}{l}\text { Illex } \\
\text { illecebrosus }\end{array}$ & $\begin{array}{l}\text { Loligo } \\
\text { pealei }\end{array}$ & $\begin{array}{l}\text { Lolliguncula } \\
\text { brevis }\end{array}$ \\
\hline Temperature $\left({ }^{\circ} \mathrm{C}\right)$ & 15 & 10 & 15 & 15 & 20 \\
\hline Weight (kg) & 0.5 & 0.4 & 0.6 & 0.6 & 0.01 \\
\hline Standard or resting metabolic rate (SMR) & 1.8 & 1.5 & 8 & 4.5 & 22 \\
\hline Active metabolic rate & 21.4 & 8.3 & 48.7 & 38 & 36 \\
\hline
\end{tabular}

Standard metabolic rate for the fish species and for L. brevis was evaluated from an extrapolation of oxygen consumption to zero swimming speed. Metabolism of the larger squid, I. illecebrosus and Loligo pealei resting on the bottom is found below the standard metabolic rate since squid are negatively buoyant and standard metabolic rate comprises the cost of maintaining position in the water column. Active metabolic rate is the rate measured at the critical swimming velocity, except for L. brevis, where it is the maximum rate of oxygen consumption measured at the highest swimming speed (after O'Dor and Webber, 1991; Lucas et al., 1993; Finke et al., 1996; Wells et al., 1988).

ommastrephid squid, migrates vast distances through the open ocean as part of its life cycle. For this reason, the most active cephalopods are included amongst the ommastrephids, rather than the loliginids.

Squid locomotion occurs by use of jet-propulsion elicited by expelling water from the mantle cavity. The mantle musculature of squid is mainly (up to $90 \%$ ) composed of circular musculature interspersed with narrow bands of radial muscle fibres (running perpendicular to the mantle surface). In addition, there is a thin layer of connective tissue on either side of the mantle ( $1 \%$ of the mantle tissue), which is important for the attachment of the radial muscles and the elastic collagen fibres $(0.5 \%)$ which act as springs, facilitating the refilling of the mantle, after a jet of water has been expelled (Gosline and Demont, 1985). In contrast to octopods, squid have no longitudinal muscle fibres in the mantle.

The various types of muscle cells in squid (Bone et al., 1981; Mommsen et al., 1981) support ventilation or jet-propelled swimming. In I. illecebrosus with a mantle cross section of approximately $6 \mathrm{~mm}$, aerobic fibres (with $47 \%$ mitochondria) comprise $14 \%(0.8 \mathrm{~mm})$ and $5 \%$ $(0.3 \mathrm{~mm})$ of the circular muscle on the outer and inner mantle surfaces, respectively. The inner section of squid mantle $(81 \%)$ is composed of anaerobic fibres (7\% mitochondria). The mitochondria-rich circular muscle fibres, which maintain continuous movement of the mantle for ventilation and constant swimming, function primarily at low swimming speeds (the maximum force generated by these cells is lower than that of the anaerobic fibres, since the number of power producing myofibrils is reduced due to the great numbers of mitochondria present). Circular and radial muscle fibres poor in mitochondria and rich in myofilaments mainly come into play when the squid is either under attack or escaping so that high speed is essential. The radial cells and collagen fibres work together to speed the reinflation of the mantle and intake of water after a jet has been expelled. When escaping attack, the mantle may even become hyperinflated, in turn producing maximum effect from the contracting circular muscle. As the circular muscle contracts, diagonal collagen fibres increase the tension and act as springs to aid the re-filling of the mantle cavity. When fully contracted the outer perimeter of the mantle is reduced by approximately $30 \%$, and at the same time the mantle wall doubles in thickness (Gosline et al., 1983; Gosline and Demont, 1985; Shadwick, 1994).

Whereas aerobic scope in the worm is negligible (see below) squid activity relies to a large extent on aerobic metabolism. Original comparisons of oxygen consumption rates in squid and fish of a similar size and mode of life used salmon as a representative high performance fish (O'Dor and Webber, 1986). Recent data available for scombrid fish emphasize that the difference in metabolic rate between mackerel and (Atlantic) salmon is small and, therefore, confirm the general conclusion that the metabolic rate of squid exceeds that of comparable ectothermal fish species (Table 1). Only the development of heterothermy or regional endothermy in scombrid fishes like tuna or in lamnid shark may lead to metabolic expenditure above the rates seen in ectothermal fish and squid (Brill, 1996; Korsmeyer et al., 1996). In compar- 
ison with the mode of swimming in ectothermic fish, oxygen consumption measurements show that jet propulsion is far more costly (Table 1). Fish set in motion a large volume of water with their undulating movement. The mechanical efficiency is high, meaning that by far the greater proportion of the caudal fin movement is converted into forward thrust (Wieser, 1986). Squid, on the other hand, use a great deal of energy to expel a relatively small amount of water. Then, after each contraction, water (flowing in the opposite direction to swimming) is sucked back into the mantle cavity. This creates turbulence which increases with speed and acts as a frictional force reducing the efficiency with which muscle power is converted to propulsion. The inefficiency of this method of propulsion is reflected in the extremely high metabolic rate of muscular squids (Table 1).

This review deals with the factors limiting the degree of muscular activity in the various squid and the sipunculid species which all display different levels of aerobic (e.g. Table 1) and anaerobic energy turnover during exercise and use anaerobic glycolysis and the phosphagen to various degrees. The paper also addresses the environmental characters limiting performance considering energy saving strategies used in different habitats.

\section{Transition to anaerobic metabolism}

Previous swim tunnel experiments in fish and squid focused on aerobic energy costs of swimming at various speeds and a determination of the critical swimming speed, i.e. the maximum velocity that a fish or squid can sustain for extended periods without evident signs of fatigue, or a determination of oxygen debt accumulated beyond this speed (e.g. Brett, 1964; Webb, 1971; Webber and O'Dor, 1985). For a study of anaerobic metabolism, its capacities and effects on tissue energy and acid-base status, typically, resting and fatigued animals or the time course of recovery from fatigue have been analysed (Pörtner et al., 1991, 1993, for reviews in fish see Milligan, 1996; Kieffer, 2000). The transition to anaerobic metabolism with rising activity levels or the progressive, correlated changes in tissue energy and acid-base status have rarely been addressed (e.g. Goolish, 1991; Burgetz et al., 1998). The reason for the scarcity of such data is that, on the one hand, online monitoring of aerobic energy expenditure was feasible early on by use of oxygen sensors, whereas, on the other hand, analyses of anaerobic contributions and associated acid-base disturbances depended on the cannulations of blood vessels or the use of invasive techniques for tissue sampling and analyses and, therefore, sacrifice of a large number of specimens during the course of the experiments. A technique for adequate invasive analysis of exercise induced transitions in intracellular acid-base status only became available in 1990 (Pörtner et al., 1990; Pörtner 1990b), which is another reason for the limited information available. The use of ${ }^{31} \mathrm{P}-\mathrm{NMR}$ techniques has been limited by accessibility of equipment for such analyses and the fact that fish had to be quiescent during the actual measurement such that online monitoring was not possible (e.g. Burgetz et al., 1998).

The present review will use data from invasive analyses of correlated changes in tissue energy and acid-base status carried out during graded levels of activity or extrapolate from data obtained in exercise protocols where animals displayed anaerobic metabolism to various degrees (Finke et al., 1996; Pörtner et al., 1991, 1993, 1996 and unpublished). Future work in this area will be much easier as only very recently in June 2001, online non-invasive monitoring of tissue energy and acid-base status at various swimming speeds and the direct determination of the critical swimming velocity became possible in fish (Atlantic cod, Gadus morhua) in a swim tunnel, by adaptation and use of ${ }^{31} \mathrm{P}-\mathrm{NMR}$ techniques (H.O. Pörtner, D.M. Webber, C. Bock, unpublished).

An analysis of the different anaerobic pathways used in a squid, L. brevis, led to the observation that, with increasing swimming speed, octopine, $\alpha$-glycerophoshate and succinate accumulation start more or less simultaneously beyond a certain swimming velocity. This indicates that an anaerobic threshold had been reached, i.e. the critical swimming speed above which anaerobic metabolism contributes to energy production (Finke et al., 1996, Fig. 1). The more or less simultaneous accumulation of these metabolites as well as the progressive decrease in phospho-L-arginine levels indicates that limited oxygen supply to mitochondria and the onset of anaerobic metabolism in both mitochondria and the cytosol go hand in hand. ATP levels fell and adenylates were degraded, while glucose-6-phosphate accumulated in the mantle muscle. This finding is quite opposite to the situation found in other invertebrate and ver- 

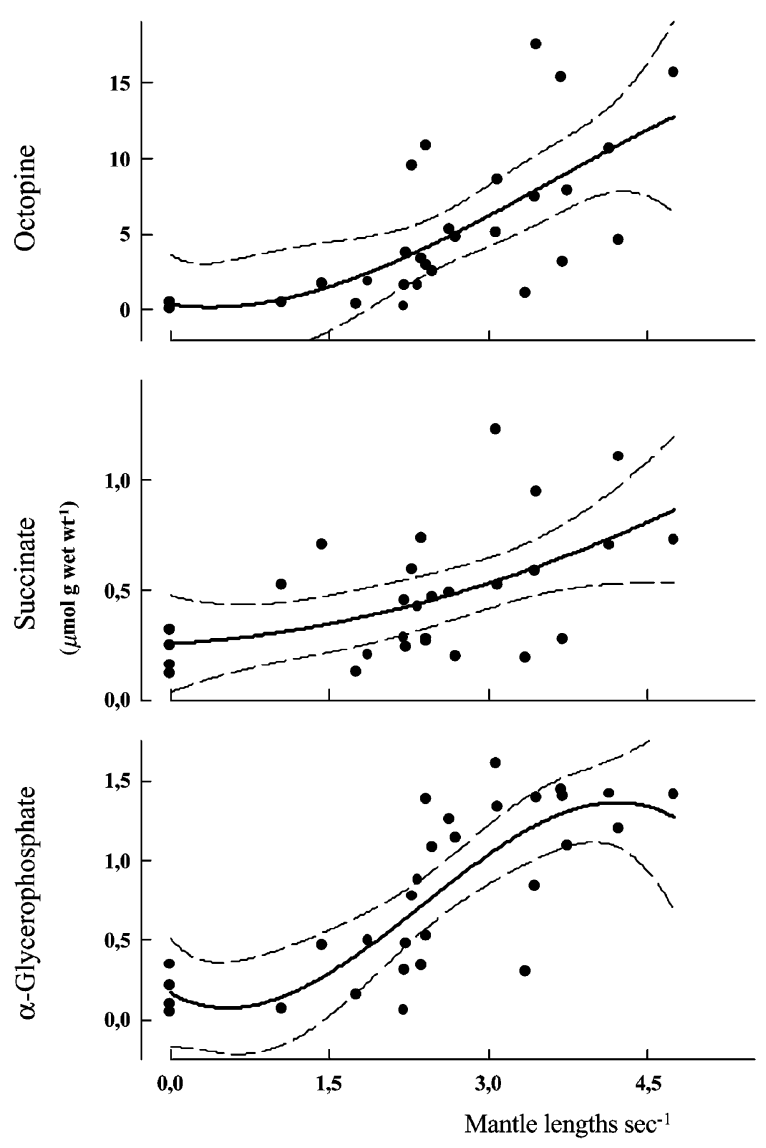

Fig. 1. Changes in octopine, $\alpha$-glycerophosphate and succinate concentrations in the mantle musculature of the brief squid, $L$. brevis sampled at different swimming speeds (after Finke et al., 1996). Lines represent second- and third-order polynomial fits and $95 \%$ confidence intervals.

tebrate species, where mitochondria remain aerobic when energy requirements in excess of aerobic energy production are covered by anaerobic metabolism during functional anaerobiosis (Grieshaber et al., 1994, for a recent example see Kemper et al., 2001). The observations in squid are in line with a much lower degree of tissue capillarisation in squid than in fish (Bone et al., 1981) and the conclusion that a large fraction of the oxygen consumption is covered by oxygen uptake via the skin on top of a maximum use of blood oxygen transport (see below). Here already, the impression arises that exercise metabolism in squid is limited by oxygen availability. This conclusion is supported by an oxygen efficient design of cephalopod muscle metabolism (Hochachka, 1994).

Whereas squid use a significant aerobic scope during muscular activity (Table 1) the marine worm $S$. nudus appears unable to raise aerobic metabolic rate to a large extent on top of the cost of ventilatory activity. Comparisons of analyses by direct and indirect calorimetry (Hardewig et al., 1991) suggested that whatever spontaneous activity was associated with anaerobic heat production at virtually constant rates of oxygen consumption. Anaerobic metabolic rate during muscular exercise was unchanged and similar metabolite levels were reached regardless of whether digging occurred under an aerated or an oxygen deficient nitrogen atmosphere (unpublished data). These observations are easily explained in a species which is active during digging in hypoxic sediments and is short in oxygen supply during any period of muscular activity except ventilation and primitive swimming movements. Accordingly, metabolism during exercise in the worm is in extreme contrast to the metabolic situation in squid, in that it is almost exclusively fuelled by anaerobic metabolism and thus limited by anaerobic capacity only and not by aerobic scope which is virtually nil in the worm.

\section{Oxygen transport}

Oxygen supply to tissues in $S$. nudus is supported by cells containing haemerythrin which are found in the large coelomic and smaller vascular cavities (Florkin, 1933; Manwell, 1960), as well as by intracellular myo-haemerythrin (Hendrickson et al., 1985). The coelomic pigment is largely used for oxygen storage, displays no Bohr effect and bound oxygen is depleted during hypoxic exposure which the animal experiences regularly during digging excursions or during low tide (Pörtner et al., 1985).

Oxygen transport to tissues in squid occurs by use of haemocyanin (for review see Mangum, 1990). This pigment is found in extracellular solution as a macromolecule, consisting of ten subunits, with eight oxygen binding sites per unit (Miller, 1994). Cephalopods, and in particular squid, have the highest concentrations of haemocyanin in the animal kingdom, with over $150 \mathrm{mg}$ protein $\mathrm{ml}^{-1}$ blood. In spite of this, the level of bound oxygen (oxygen binding capacity) at 1-3 mmol $1^{-1}$, remains below the $4-5 \mathrm{mmol}^{-1}$ found in fish. For optimised oxygen transport, especially the haemocyanins of muscular squid display a strong $\mathrm{pH}$ dependence for oxygen binding, with Bohr coefficients $\Delta \log P_{50} / \Delta \mathrm{pH}$ less than -1 


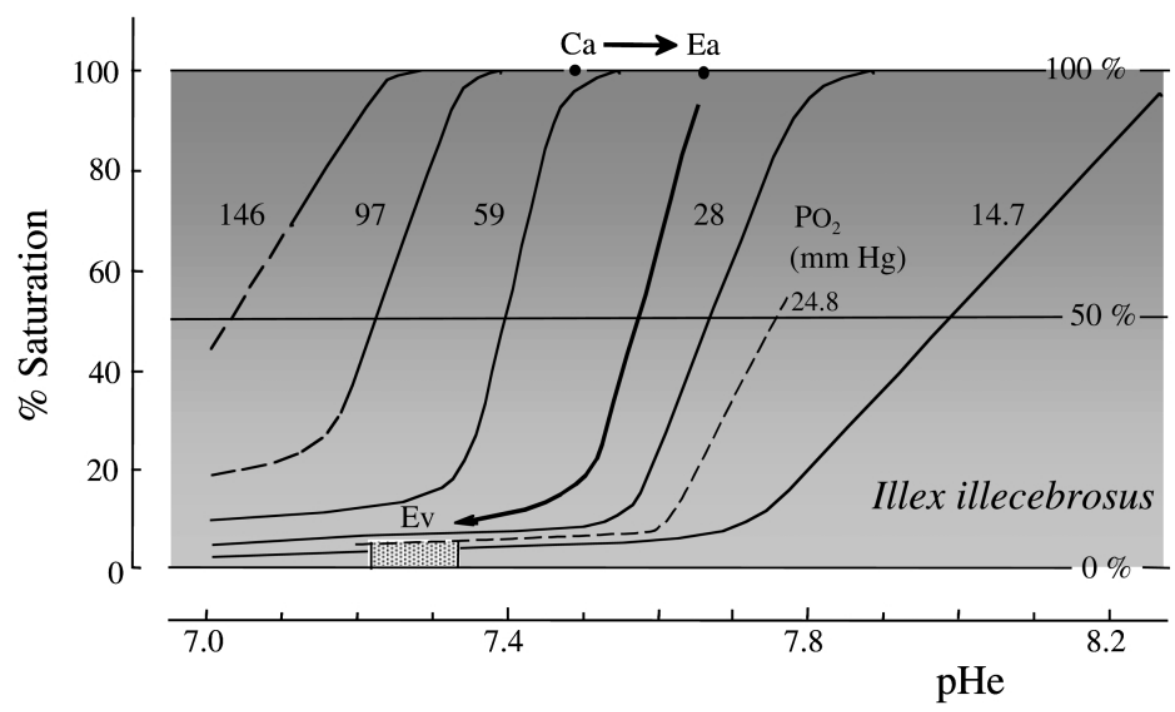

Fig. 2. Changes in haemocyanin percent oxygen saturation between control conditions and exercise in the squid I. illecebrosus, depicted in a $\mathrm{pH} /$ saturation diagram (Pörtner, 1990a). The shift in arterial blood $\mathrm{pH}$ between control conditions (Ca) and exercise (Ea) mirrors the protective base release into the blood (Fig. 3). Note the maximum use of haemocyanin bound oxygen in venous mantle blood (Ev, based on model calculations by Pörtner, 1994 using data compiled by Pörtner et al., 1991, 1993).

(Bridges, 1994). Highly $\mathrm{pH}$ dependent cooperativity gives rise to an $S$-shaped $\mathrm{O}_{2}$-binding curve with a particularly steep slope shifted to high levels of $P_{\mathrm{O}_{2}}$, i.e. oxygen affinity is low. With high $P_{50}$ values the buffer range of $P_{\mathrm{O}_{2}}$ is shifted to high values supporting a high $P_{\mathrm{O}_{2}}$ gradient and, in consequence, a high flow of oxygen between blood and mitochondria (Pörtner, 1990a, 1994; see Fig. 2 for a depiction of arterial and venous $\mathrm{pH}$ and $P_{\mathrm{O}_{2}}$ values in a $\mathrm{pH}$ saturation diagram). With Bohr and Haldane coefficients $\leqslant-1$ proton exchange at the protein level would cause $\mathrm{pH}$ to rise between arterial and venous blood, unless production of surplus $\mathrm{CO}_{2}$ occurs higher than expected from normal RQ values. This is only possible if a major proportion of the oxygen enters through the skin instead accounting for additional $\mathrm{CO}_{2}$ production (Pörtner, 1994). The necessity for complementary skin oxygen uptake is also underlined by the observation that the use of blood borne oxygen is maximal (Fig. 2), that the circulatory system would not be able to pump the required quantity of blood, and that the capillarisation of the mantle muscle is insufficient (see above). The mitochondrion-rich muscle cells are situated on the inner and outer mantle surfaces and are supplied with oxygen directly through an extremely thin skin. Continuous movement of water over the inner and outer mantle surfaces reduces the formation of oxygen poor boundary layers. Oxygen uptake via the skin is not just dependent on passive diffusion, since the proportion provided by this form of respiration is too great (at times over $50 \%$ of the total oxygen uptake in the mantle of I. illecebrosus). It may be enhanced by the movement of the tissue fluids, produced by the constant muscle activity (and the repeated $100 \%$ alteration in the cross section of the mantle wall mentioned above; Gosline and Demont, 1985, for further details see Pörtner, 1994).

The large $\mathrm{pH}$ sensitivity of the haemocyanin and the maximum use of blood oxygen transport (Fig. 2) makes especially ommastrephids quite sensitive to fluctuating ambient $P_{\mathrm{CO}_{2}}$ and $P_{\mathrm{O}_{2}}$ levels (Pörtner, 1990a, 1994). Due to their high oxygen requirement and the high $\mathrm{pH}$ dependence of oxygen binding, they rely on a constantly high level of oxygen and a low level of carbon dioxide in order to safeguard their oxygen transport. The danger of a drop in arterial $\mathrm{pH}$ during active periods is reduced by release of a surplus of bicarbonate into the blood (Fig. 3), raising $\mathrm{pH}$ between control and exercise (as depicted in Fig. 2) and thereby also increasing oxygen affinity (Pörtner, 1994, see below). As suggested above all of these considerations are in line with a limiting role of ambient oxygen levels and indicate 

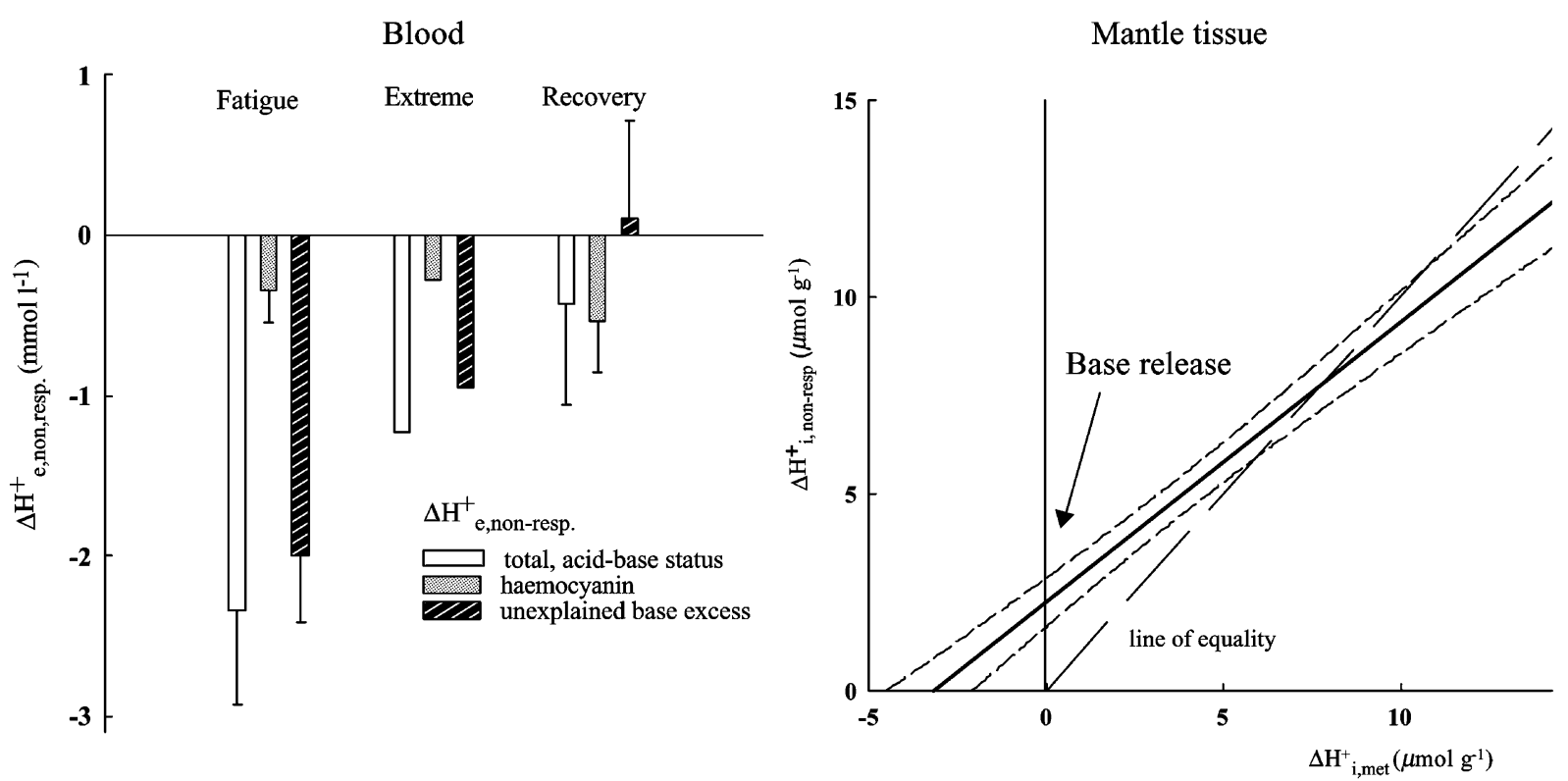

Fig. 3. Comparison of non-respiratory proton quantities in blood and mantle tissue of the squid I. illecebrosus with those bound during haemocyanin deoxygenation (left, for blood) or those turned over in metabolism (right, for mantle tissue). A base excess found in the blood is mirrored by the net release of base from the mantle tissue (after Pörtner, 1994).

that these animals could only achieve such a high level of activity after their ancestors had lost their shell (cf. Wells, 1994). However, as squid increase in size, the proportion of the oxygen supply obtained via the skin must become less owing to the short distances covered by diffusion. This seems likely, since the metabolic rate per unit weight drops and the animals can manage almost entirely on the oxygen supplied by the blood. Interestingly, the Bohr coefficient for giant squid (Architeuthis monachus) with a value of -0.8 (Brix et al., 1989), is in excess of -1 , which means that the pigment's $P_{\mathrm{O}_{2}}$ buffer function is nonetheless guaranteed. The oxygen uptake over the skin is probably also lower in Octopus vulgaris and Sepia. With Bohr factors below -1, these species use an alternative and unusual method of venous acidification: their haemocyanin binds $\mathrm{CO}_{2}$ together with oxygen in the gills and transports it to the tissues (Lykkeboe et al., 1980). However, nothing is known about the molecular basis of this particular method of $\mathrm{CO}_{2}$ binding.

\section{Environmental constraints for muscular activity: oxygen and temperature}

The discussion above already suggests that, in the case of squid, oxygen availability to tissues limits performance levels, whereas the worm almost exclusively relies on anaerobic resources for muscular exercise. As outlined below, oxygen limitations already become effective under resting conditions in the case of the worm, whereas in the case of squid, such limitations seem to be largely effective on aerobic scope. Not only in the worm's habitat but also in some natural habitats of squid oxygen levels may fluctuate as reported for the brief squid, $L$. brevis. These animals not only enter shallow coastal waters characterized by larger fluctuations of environmental parameters like temperature and salinity, but L. brevis were also found in hypoxic bottom waters with a $P_{\mathrm{O}_{2}}$ of $2.1 \mathrm{kPa}$ by use of a remotely operated vehicle (Vecchione, 1991). They were observed to be quite active under these conditions and may have entered these waters for feeding and/or escape excursions. Furthermore, catches by trawling indicated a high abundance in waters with a $P_{\mathrm{O}_{2}}$ between 4.3 and $8.6 \mathrm{kPa}$, however, animals were no longer present when oxygen tensions fell below $2 \mathrm{kPa}$ at temperatures between 25 and $29{ }^{\circ} \mathrm{C}$ (Vecchione, 1991 and personal communication).

Recently, the critical $P_{\mathrm{O}_{2}}$ was determined for $L$. brevis (Zielinski et al., 2000), the only analysis available for squid. The critical $P_{\mathrm{O}_{2}}$ is characterized by the onset of anaerobic energy metabolism 
and indicates oxygen limitations under resting conditions when animals exhibit standard metabolic rates (SMR) (Pörtner and Grieshaber, 1993). The data for $L$. brevis reveal a rather high critical oxygen level $\left(P_{\mathrm{c}}\right)$ of $8-10 \mathrm{kPa}$ at $20{ }^{\circ} \mathrm{C}$, which apparently contradicts the findings that these animals are able to enter and stay in hypoxic water layers. However, an energy saving mode of jet propulsion may allow this species to dive into hypoxic waters (see below). This strategy will prolong the period during which anaerobic resources can be used. Nothing is known in this respect for other squid species. As discussed earlier the maximum use of oxygen resources and the high sensitivity of blood oxygen transport suggest that I. illecebrosus is intolerant to even moderate hypoxia although the $P_{\mathrm{c}}$ has not been quantified.

Tolerance to fluctuating temperatures may be intimitely linked with the question of hypoxia tolerance. Insufficient capacity of ventilatory and circulatory mechanisms to cover tissue oxygen demand are seen to define the first line of thermal intolerance (Pörtner et al., 1998; Pörtner, 2001, 2002a). As outlined previously, the critical temperature, defined by the onset of anaerobic metabolism, is just above the range of ambient temperatures found in the natural environments of $L$. brevis, whereas the upper limit found for an Antarctic octopod is considerably above ambient (Pörtner and Zielinski, 1998). Critical temperatures will decrease during conditions of progressive hypoxia (Pörtner, 2001). Considering the environmental data set available for $L$. brevis, these considerations emphasize that these squid operate at their functional and environmental limits.

\section{Energy savings in squids}

As concluded above, the maximization of performance characteristics and oxygen demand in today's muscular squid was only possible after the ancestors of today's shell-less species lost their shell and thereby, mechanical protection from predators as well as buoyancy by means of the shell's gas-filled chambers. These developments occurred under increasing competition and threat of attack from vertebrates. As much as life in hypoxic environments limits aerobic energy turnover, a conclusion valid for the worm but also, more generally, for fish and cephalopods living, for example, in the oxygen minimum layer (Childress and Seibel, 1998) the high $\mathrm{O}_{2}$ and low $\mathrm{CO}_{2}$ concentrations in the upper pelagic zone at high food availability supported a maximization of energy turnover and, correspondingly, growth rates. Accordingly, loss of the shell and development of a constantly high level of activity went hand in hand although, at times, squids are able to rest on the sea bed, as observed even in the ommastrephid I. illecebrosus.

Maximizing energy turnover applies strictly only to the most active forms, that is the ommastrephids such as I. Illecebrosus, which cover huge stretches of open ocean when migrating or in search of food. Loliginids like L. brevis reach limits of performance at lower levels in environments characterized by larger fluctuations of abiotic parameters. L. pealei also lives in a 'complex' coastal environment and is not dependent on maintaining such high velocities when catching prey or escaping attack. Owing to shorter distances they also do not need the stamina that I. illecebrosus does. A well-developed fin is most useful in coastal waters, for instance close to the sea bed, when the ability to navigate well at low speeds becomes important. The fin with its undulating beat bridges the inherent pauses in between jets (refilling phase) and smoothes out and stabilises movement. In coastal environments squid can even make use of upwelling currents to counteract sinking. As suggested for Loligo forbesi the fin may take on an additional role as a hydrofoil (O'Dor et al., 1994). Since the same physical principles apply as in fish locomotion (see above) the use of a fin saves energy. The more developed the fin, the more it is involved in propulsion. However, the degree of attainable thrust is much lower than for fish, since only a small mass of muscle is involved and there is no strengthening of the muscle comparable to the effect of the spinal column in fish. Thus the fin only saves energy at low speeds. Both Sepia officinalis and L. pealei use their fin at low speeds which results in a lower energy requirement than in I. illecebrosus (O'Dor and Webber, 1991). As the fin increases in size, it increases drag and energy expenditure by hampering the stream-lined body shape (cf. O'Dor and Webber, 1991; Hoar et al., 1994). Accordingly, when it is of prime importance to reach high speeds, as is the case for $I$. illecebrosus, there is only a small fin which enhances a stream-lined body shape. As a jet of water is expelled the remaining fin is flattened against the mantle, thus reducing body drag. 
A different strategy to save energy appears to exist in L. brevis (Finke et al., 1996). This loliginid lives in the brackish waters of the Gulf of Mexico. As a small coastal and inshore species it usually does not need to cover long distances searching for prey or in escape responses, a fact reflected in its low critical swimming speed (Finke et al., 1996). At increased velocities, the animals oscillate between periods of high and low muscular activity as indicated by the recording of low and high pressure jets. The relatively small difference between resting and active oxygen consumption (Table 1) suggests that this behaviour reduces transport cost and permits a longer term net use of anaerobic resources when speed exceeds the critical value or when the squid dive into hypoxic waters (see below).

In the deep sea, there is not such close competition from similar-sized vertebrates. Since food density and temperatures are lower than in continental seas, a very economical way of life is warranted for all life forms eliminating the competitive pressure to maximize performance. In midwater fish and squid energy savings are supported by neutral buoyancy mechanisms which counteract the danger in sinking into deeper waters and, in the case of squid, alleviate the necessity to continuously use jet propulsion for the maintenance of position in the water column. Some squid store fat obtained from their diet in the midgut gland to increase their buoyancy. However, the majority of neutrally buoyant squid have altered the ionic composition of their body fluids to compensate for the high density of their tissues (Clarke et al., 1979). Seawater from the open ocean has a density of between 1.023 and 1.028 $\mathrm{kg} \mathrm{l}^{-1}$. Densities for whole specimens of 1.06 and $1.076 \mathrm{~kg} \mathrm{l}^{-1}$ have been recorded for $L$. pealei and I. illecebrosus, respectively (O'Dor and Webber, 1991). To compensate for the high specific density of their tissues, deep sea species reduce the sulphate concentration of part of their body fluids and exchange a relatively large proportion of their sodium chloride for ammonium chloride (Voight et al., 1994). A solution of ammonium chloride of seawater osmolarity has a density of $1.01 \mathrm{~kg} \mathrm{l}^{-1}$. In order to achieve neutral buoyancy they therefore need to replace a large percentage of their body fluids with solutions containing ammonia. To avoid potential ammonium toxicity, the ammonium chloride solution in cephalopods is stored in fluid filled chambers which are completely separated from the blood (for review see Voight et al., 1994). Due to the vacuolisation of the mantle tissue, the giant squid have a lower proportion of active muscle in comparison with their more agile shallow water relatives. For this reason, and due to the sizedependence of oxygen transfer (see above), these giant squid can never attain the same level of activity as the smaller more muscular species, a conclusion recently confirmed by Webber et al. (2000).

\section{6. $\mathrm{pH}$ regulation and muscular energetics}

The question arises how the constraints on activity levels and aerobic energy turnover imposed by environmental conditions extend to the use and rate of anaerobic energy turnover. In general, muscular metabolism in marine invertebrates has all the characteristics well known for metabolism in vertebrate striated muscle (e.g. Fitts, 1994), however, glycolytic end products different from lactate are characteristic for many molluscs, annelids and lower invertebrates. Opines are formed instead which are condensation products of pyruvate with amino acids (e.g. alanine for alanopine, glycine for strombine, arginine for octopine, see Grieshaber et al., 1994, for review). Both the squids and the worm form octopine during muscular exercise. During muscular activity beyond the anaerobic threshold the formation of lactate is known to lead to acidification of the tissues and blood owing to proton formation in the glycolytic pathway (Hochachka and Mommsen, 1983; Pörtner et al., 1984a; Pörtner, 1987). Although opines by themselves are much weaker acids than lactic acid, the net generation of the pyruvate moiety in glycolysis prior to condensation always causes acidosis (Pörtner, 1987). L-arginine consumed in octopine formation is provided by the hydrolysis of L-arginine phosphate (Eq. (1) and Eq. (2), stoichiometry for Eq. (1) is simplified, cf. Pörtner, 1987).

$$
\begin{aligned}
& \text { Phospho-L-arginine }\left(\mathrm{PLA}^{-}\right)+\mathrm{MgADP}^{-} \\
& +\mathrm{H}^{+} \\
& \Leftrightarrow \text { L-Arginine }\left(\mathrm{L}^{-} \mathrm{Arg}^{+}\right)+\mathrm{MgATP}^{2-} \\
& \text { L-Arginine }(\mathrm{L}-\mathrm{Arg})^{+}+0.5 \text { glucose } \\
& \Leftrightarrow \text { octopine }+\mathrm{H}^{+}
\end{aligned}
$$

Accordingly, octopine formation was shown to cause acidosis in squid muscle, in accordance with the view that the net process of glycolytic proton 
production is not different between lactate or opine production (Pörtner et al., 1991, 1993, 1996).

Phosphagen breakdown and anaerobic glycolysis are predominantly responsible for metabolic changes in the intracellular acid-base status starting beyond the anaerobic threshold. Net ATP breakdown contributes further protons. Metabolic processes which reduce acidosis during activity not only include phosphagen degradation, but also the deamination of AMP or adenosine in the ATP degradation pathway or the metabolism of dicarboxylic acids (malate, aspartate) in the early stages of anaerobic metabolism in the mitochondria, which occurs when excessive oxygen consumption cannot be compensated for by increased oxygen supply (Pörtner, 1994).

Unlike lactate, octopine does not usually leave the intracellular space. An in depth study comparing all metabolic protons with changes in the acid-base balance was able to track the fate of metabolically produced protons (Pörtner, 1994). Virtually all the metabolic protons remained within the muscle cells. During the onset of exercise, the tissue even lost base to the extracellular space, illustrated by an early deviation of the correlated changes in non-respiratory and metabolic proton quantities from the line of equality in Fig. 3. This deviation indicates an early intracellular non-respiratory acidosis in the mantle $\left(\Delta \mathrm{H}_{\mathrm{i}, \text { non-resp }}^{+}<0\right)$ when metabolic proton production does not yet contribute $\left(\Delta \mathrm{H}_{\mathrm{i}, \text { met }}^{+}=0\right)$. This base deficit is mirrored by a base excess in the blood maintained during fatigue which is largely unexplained by proton quantities bound during haemocyanin deoxygenation. During increasing metabolic acidification the base excess in the blood was reduced, this time mirrored by a lower slope of the correlated changes in non-respiratory and metabolic proton quantities compared to the line of equality. This difference in slope led to a crossover at elevated levels of tissue acidosis and finally to a somewhat larger metabolic compared to non-respiratory proton quantities owing to some proton release from the mantle tissue.

As a corollary, modern shell-less cephalopods appear to be different from most other animals investigated, since they primarily regulate the extracellular, not intracellular, acid-base balance and maintain similar values of extracellular and intracellular $\mathrm{pH}$ under control conditions (cf. Fig. 2 and Fig. 4), with a much lower extracellular $\mathrm{pH}$ than found in fish. This immediately suggests that
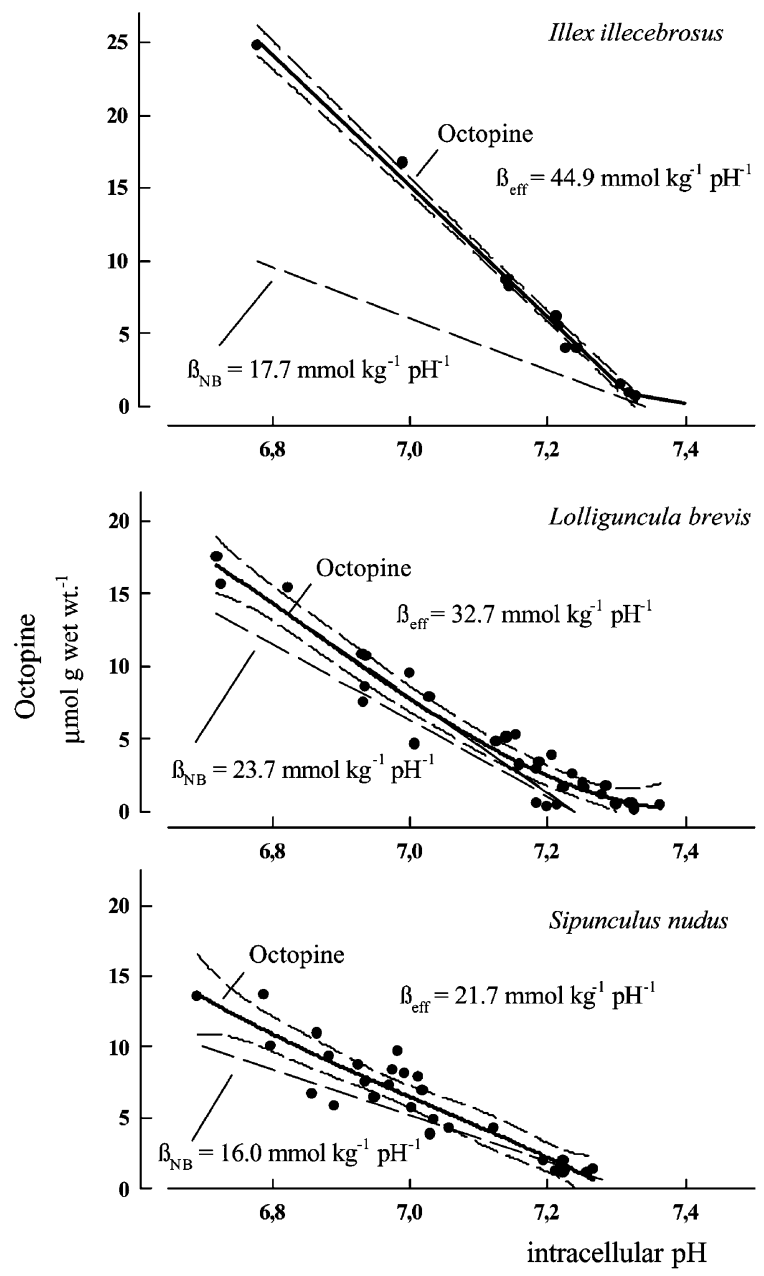

Fig. 4. Correlated changes in $\mathrm{pH}_{\mathrm{i}}$ and octopine levels in two squid species (I. illecebrosus, L. brevis) and a worm ( $S$. nudus). Lines represent second- and third-order polynomial fits and $95 \%$ confidence intervals. (Data by Pörtner et al., 1991, 1996 and unpublished, for a discussion of buffer values $\beta$ see text, NB, non-bicarbonate, eff, effective).

a value of extracellular and intracellular $\mathrm{pH}$ close to 7.4 (at $15{ }^{\circ} \mathrm{C}$ ) may have evolved for optimised $\mathrm{pH}$ dependent protein, in this case haemocyanin function. Also, squid avoid acidification of the extracellular space, even when high levels of octopine are produced (Fig. 3). This strategy becomes understandable in the light of maximized oxygen transport by the haemocyanin which depends upon maximized fine control of extracellular acid-base status and protection of haemocyanin function from metabolic acidification (Fig. 2). Initial base release enhances and secures arterial haemocyanin oxygen binding. Respiratory acidification of the blood in the mantle tissue leads 
to maximum use of haemocyanin bound oxygen on each return. The non-release of opines observed in the squid as well as in the sipunculid worm suggests that $\mathrm{H}^{+}$and end products are removed in situ during recovery (Pörtner, 1993). In squid mantle muscle the removal of octopine and $\mathrm{H}^{+}$ appears to be tightly coupled (Pörtner, 1994; Pörtner et al., 1991, 1993, 1996).

At peak activity, L. pealei produced far less octopine than Loligo vulgaris (Grieshaber and Gäde, 1976), I. illecebrosus or L. brevis and experienced less intracellular acidosis (Pörtner et al., 1991, 1993, 1996). I. illecebrosus accumulated up to $25 \mu \mathrm{mol}$ octopine $\mathrm{g}^{-1}$ fresh weight, coincident with a reduction in intracellular $\mathrm{pH}$ by up to $0.6 \mathrm{pH}$ units (Fig. 4, Table 2), whereas in $L$. brevis, octopine accumulations up to $18 \mu \mathrm{mol}$ octopine $\mathrm{g}^{-1}$ fresh weight led to a maximum deflection of intracellular $\mathrm{pH}$ by 0.57 units with less phosphagen hydrolysis counteracting the acidification than in I. illecebrosus (Fig. 5, Table 2). In $S$. nudus, changes in intracellular $\mathrm{pH}$ of up to $0.5 \mathrm{pH}$ units occurred, in correlation with octopine levels of up to $14 \mu \mathrm{mol} \mathrm{g}{ }^{-1}$ fresh weight at even less use of the phosphagen (Table 2).

Work on isolated contracting muscle showed that ATP content is initially maintained at the expense of phosphagen breakdown leading to intracellular alkalosis (Eq. (1)). Glycolytic ATP and $\mathrm{H}^{+}$production became predominant during maintained muscle activity with the result that $\mathrm{pH}_{\mathrm{i}}$ fell below control levels (Chih and Elllington, 1985). These results appear to contradict findings in vivo, where a highly significant linear correlation between changes in intracellular $\mathrm{pH}$ and octopine accumulation started early on (Fig. 4, Pörtner et al., 1991, 1996). The slope of this relationship reflects the response of the tissue to glycolytic

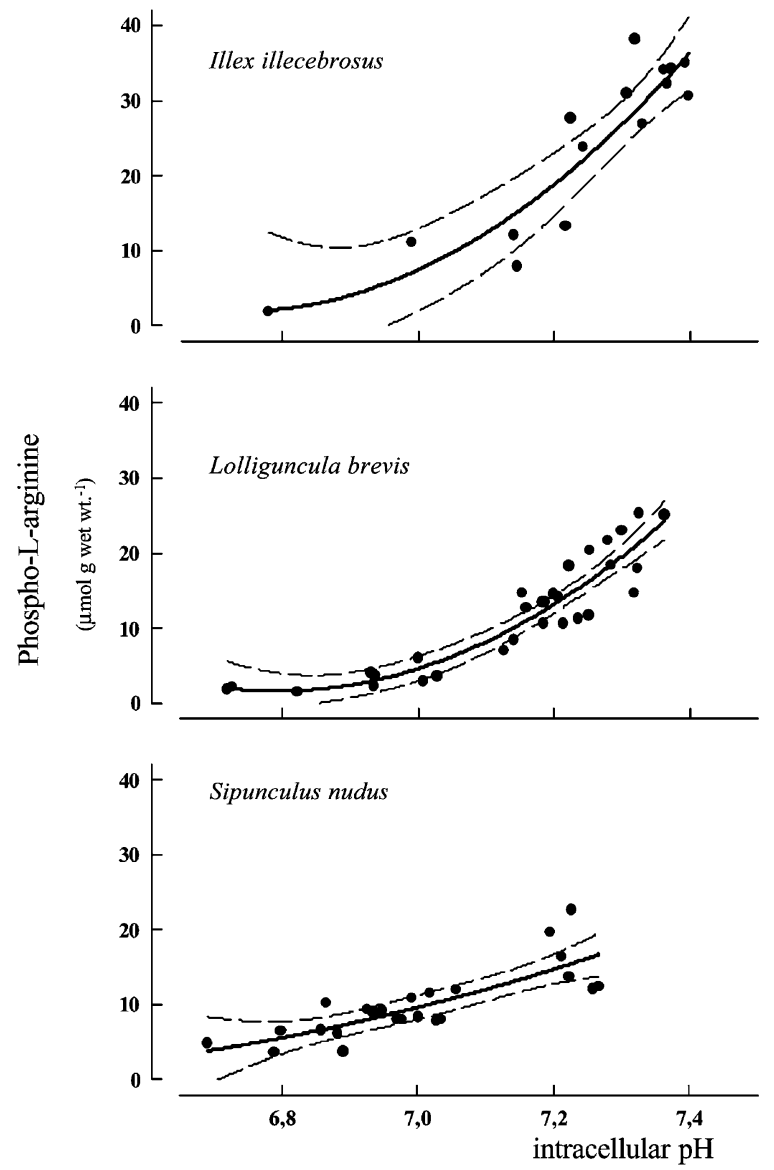

Fig. 5. Correlated changes in muscle intracellular $\mathrm{pH}$ and phospho-L-arginine levels in two squid species (I. illecebrosus, $L$. brevis) and a worm (S. nudus). Lines represent second- and third-order polynomial fits and 95\% confidence intervals. (Data by Pörtner et al., 1991, 1993, 1996 and unpublished).

acidification in vivo as it results from summed reactions of intracellular physicochemical and metabolic buffering processes and, with the exemption

Table 2

Maximum acidification and energetic parameters limiting performance of three squid species and a sipunculid worm during functional anaerobiosis (after Pörtner, 1993; Pörtner et al., 1996 and unpublished)

\begin{tabular}{|c|c|c|c|c|c|}
\hline & $\begin{array}{l}\text { Illex } \\
\text { illecebrosus }\end{array}$ & $\begin{array}{l}\text { Loligo } \\
\text { pealei }\end{array}$ & $\begin{array}{l}\text { Lolliguncula } \\
\text { brevis }\end{array}$ & $\begin{array}{l}\text { Sipunculus } \\
\text { nudus }\end{array}$ & \\
\hline$\Delta \mathrm{pH}_{\mathrm{i}}$ & -0.6 & $>-0.1$ & -0.57 & -0.53 & \\
\hline$\Delta \mathrm{PLA}$ & -31.2 & -22.5 & -18.8 & -12.0 & $\mu \mathrm{mol} \mathrm{g}^{-1}$ \\
\hline$\Delta \mathrm{L}$-arginine & 14.9 & 28.0 & 0.0 & 2.0 & $\mu \mathrm{mol} \mathrm{g}^{-1}$ \\
\hline$\Delta \mathrm{ATP}$ & -2.3 & -3.8 & -2.5 & -1.3 & $\mu \mathrm{mol} \mathrm{g}^{-1}$ \\
\hline$\Delta \mathrm{ADP}$ & 1.3 & 2.4 & 1.0 & 0.0 & $\mu \mathrm{mol} \mathrm{g}^{-1}$ \\
\hline$\Delta \mathrm{AMP}$ & 0.7 & 2.3 & 0.7 & 0.0 & $\mu \mathrm{mol} \mathrm{g}^{-1}$ \\
\hline$\Delta \mathrm{d} G / \mathrm{d} \xi$ & 13.8 & 14.0 & 12 & 6.0 & $\mathrm{~kJ} \mathrm{~mol}^{-1}$ \\
\hline Minimum $\mathrm{d} G / \mathrm{d} \xi$ & -42 & -42 & -45 & -49 & $\mathrm{~kJ} \mathrm{~mol}^{-1}$ \\
\hline
\end{tabular}


of squid, proton equivalent ion exchange between tissue and extracellular fluid. Evidently, the compensatory or additive processes affect proton balance in such a way that they become involved early on and in addition to anaerobic glycolysis, without fully compensating for the acidosis. They either take place at a constant rate, with no disruption of the linear relationship, or are themselves directly dependent on $\mathrm{pH}_{\mathrm{i}}$ in a way that a change in the linear slope results for the whole range of $\mathrm{pH}_{\mathrm{i}}$. The direct dependence of L-arginine phosphorylation on $\mathrm{pH}_{\mathrm{i}}$ is indicative that release of inorganic phosphate during phosphagen hydrolysis has a direct effect on the degree of acidification caused by octopine (Fig. 5). Within a certain $\mathrm{pH}$ range, the contribution of inorganic phosphate to buffering changes linearly with $\mathrm{pH}$ (Pörtner et al., 1996). An effective buffer value $\beta$ results (Fig. 4 ), which is higher ( $\beta N B)$ than that measured under control conditions and indicates how proton consuming processes in metabolism collectively reduce the degree of acidification (Pörtner et al., 1996).

Although at first sight mantle tissues of the ommastrephid squid, I. illecebrosus and the loliginid squid, L. brevis as well as the muscle of the digging worm appear similar in their metabolic response to exercise above the anaerobic threshold, differences become obvious when the relationships between octopine levels and intracellular $\mathrm{pH}$ are compared (Fig. 4). The slopes of the in vivo titration curve (effective buffer line) are closer to the slopes of the non-bicarbonate buffer line in $L$. brevis and $S$. nudus than in I. illecebrosus. Most of this difference can be explained by slower phosphagen turnover in L. brevis and S. nudus in addition to a reduced amount of phosphagen being available (Fig. 5). Looking at the effects of control $\mathrm{pH}$ on phosphagen levels, PLA levels were found higher in Illex than in Lolliguncula and Sipunculus. Following Eq. (1) this is likely supported by higher control $\mathrm{pH}_{\mathrm{i}}$ values (Fig. 5) and sufficiently high L-arginine levels. Less PLA depletion and, as a consequence, less inorganic phosphate accumulation in L. brevis and S. nudus explains the lower buffering of glycolytic protons and is related to lower levels of free ADP than in I. illecebrosus and L. pealei (Finke et al., 1996; Pörtner et al., 1996). Obviously, L. brevis and S. nudus utilize acidification rather than the accumulation of free ADP to elicit phosphagen transphosphorylation and ATP buffering, whereas I. illecebrosus uses
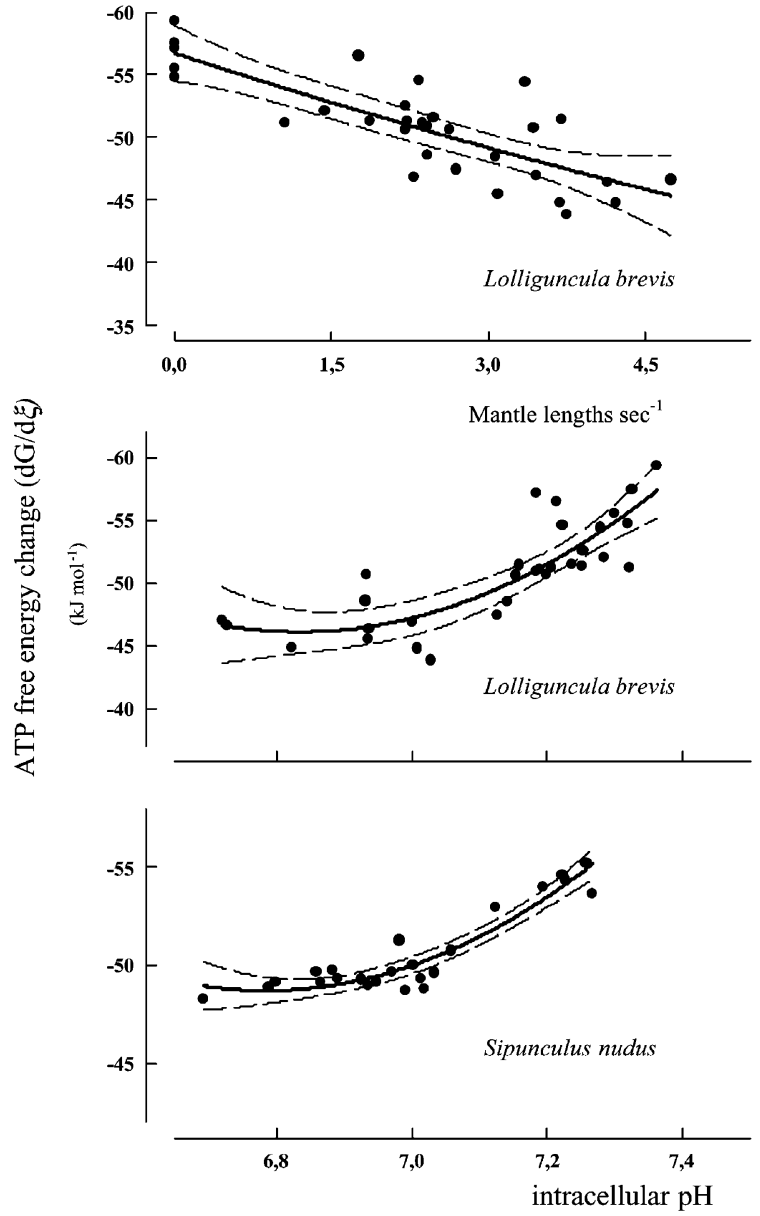

Fig. 6. Correlated changes in swimming velocity (mantle lengths $\mathrm{s}^{-1}$ ) or muscle intracellular $\mathrm{pH}$ and the Gibbs's free energy change of ATP hydrolysis in a squid species (L. brevis) and a worm ( $S$. nudus). Lines represent 2 nd and 3 rd order polynomial fits and 95\% confidence intervals. (Data by Pörtner et al., 1996 and unpublished).

both. In L. pealei accumulation of total and free ADP was far more expressed (Table 2) and triggers phospho-L-arginine depletion (Eq. (1)) with less acidosis contributing than in the other species.

The extensive breakdown of ATP to ADP in $L$. pealei illustrates that this species is less well equipped to withstand greater physical demands than I. illecebrosus (Pörtner et al., 1993). This is what would be expected from the 'quieter' way of life of a loliginid which extensively uses its fins. Evidently, the acidosis (in I. Illecebrosus, L. brevis and $S$. nudus) protected ATP from being largely degraded and thereby supported extended muscular activity (see also Fig. 7 below, and Hartmund and Gesser, 1995). 


\section{Parameters extending and limiting work intensity and muscle function}

The onset of anaerobiosis beyond the critical swimming speed appears as the key to an understanding of fatigue in squid mantle muscle. A fall in $\mathrm{pH}$ affects the energy status of the muscle cells which is not only related to ATP levels but quantified as the Gibb's free energy change of ATP hydrolysis $(\mathrm{d} G / \mathrm{d} \xi)$. This parameter is seen to limit the function of cellular ATPases (Kammermeier et al., 1982; Pörtner, 1993; Combs and Elllington, 1996). The term 'ATP free energy change' is derived from various parameters including intracellular $\mathrm{pH}$ and cellular concentrations of ATP, free ADP, inorganic phosphate, and free magnesium (Pörtner et al., 1996). Assuming constant levels of all of these parameters, $\mathrm{pH}$ by itself causes a rather small 'drop' in standard and in vivo ATP free energy change values by approximately $2 \mathrm{~kJ} \mathrm{~mol}^{-1}$ with a minimum below $\mathrm{pH} 7.0$ (Pörtner, 1993). In squid mantle and sipunculid muscle, a much larger change occurs which, though partly caused by the acidosis, tends to follow the depletion of ATP, the phosphagen and the accumulation of ADP and inorganic phosphate (Fig. 6). These relationships await closer investigation in vertebrates.

The minimum value for ATP free energy change may contribute to the onset of contractile failure or fatigue independent of $\mathrm{pH}$. This conclusion is supported by the observation that the respective change in energy status was similar in fatigued $I$. illecebrosus and $L$. pealei although $\mathrm{pH}$ fell by approximately $0.6 \mathrm{pH}$ units in I. illecebrosus mantle but only by less than $0.1 \mathrm{pH}$ units in L. pealei (Pörtner et al., 1993, 1996; cf. Table 2). As a corollary, a drop in ATP free energy occurs to the same extent in fatiguing muscle regardless of whether $\mathrm{pH}$ falls at the same time or not (cf. Table 2). This low level may actually represent the limiting level of ATP free energy change. At the same time, an intracellular acidosis as seen in $I$. illecebrosus (and L. brevis) may help to protect ATP from being degraded (Pörtner et al., 1993, 1996). With a similar change and the same minimal value of ATP free energy change as in $I$. illecebrosus, more ATP was depleted in L. pealei and more ADP and AMP accumulated. An acidosis, although decreasing the actual value of the free energy change of ATP hydrolysis to some extent (see above), is in most cases associated

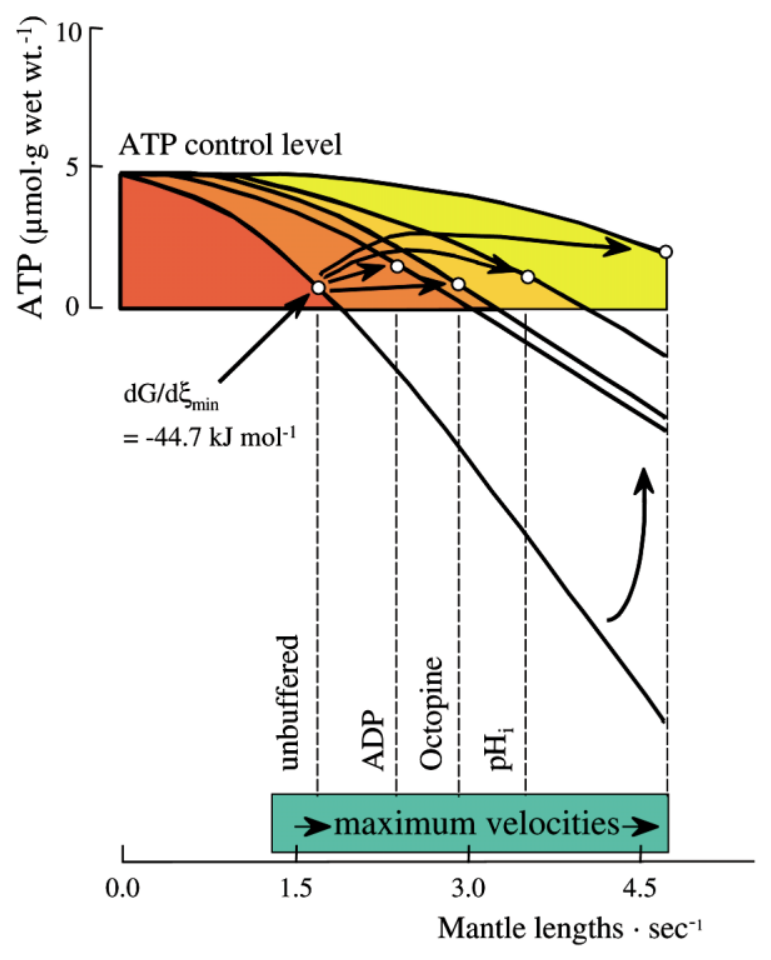

Fig. 7. Model of the delayed drop in ATP free energy and the increase in maximum swimming speed depending on the buffering of ATP levels by use of the phosphagen, calculated to be elicited by each, the drop in $\mathrm{pH}_{\mathrm{i}}$, the accumulation of free ADP, the removal of L-arginine during octopine formation and, finally, the combined action of all three parameters (modified after Pörtner et al., 1996).

with complementary ATP production by glycolysis and by triggering the use of phospho-L-arginine, thereby compensating for this apparent disadvantage and delaying the progressive depletion of ATP levels and the fatal decrease in ATP free energy change.

Fig. 7 models these processes as they depend upon each individual parameter, the decrease in intracellular $\mathrm{pH}$, the accumulation of free ADP and the removal of arginine by octopine in the brief squid L. brevis (Pörtner et al., 1996). Unbuffered ATP depletion calculated as being equivalent to the measured depletion of high energy phosphates (the sum of ATP and PLA levels) would cause the ATP free energy change to fall early to the observed minimum and would not allow the animals to reach a higher than the critical swimming speed. It becomes obvious that the accumulation of free ADP causes significant ATP buffering and an increase in the maximum swim- 
ming velocity but the effect is less than the transphosphorylation caused individually by each, the formation of octopine and, even more so, the fall in $\mathrm{pH}_{\mathrm{i}}$. The combined and integrated action of all mechanisms finally allows the animals to raise performance and exceed the critical swimming speed (1.5 mantle lengths $\mathrm{s}^{-1}$ ) by a factor of approximately three (Pörtner et al., 1996).

The model emphasizes to what extent buffering of ATP levels is linked to a buffering of ATP free energy change values which are decreased already by the accumulation of inorganic phosphate associated with phosphagen depletion. Actually, this decrease can be considered advantageous, since both the acidosis and the accumulation of inorganic phosphate have some protective effect on ATP concentrations. As a consequence, the minimum level of ATP free energy is reached at higher ATP contents with the use of the phosphagen than without (Fig. 7).

The accumulation of inorganic phosphate is very likely involved in limiting the degree of muscular activity or reducing the maximum swimming velocity, processes which we tend to interpret as signs of fatigue (Fitts, 1994). This may actually start to slow muscular performance at levels of ATP free energy higher than the minimum, limiting level. For example, fatigue or a reduction in motor activity is seen in L. brevis and especially $S$. nudus at higher values of the Gibb's free energy change of ATP hydrolysis than in I. illecebrosus (Table 2). This may be related to Lolligunculas's ability to dive into hypoxic waters (Vecchione, 1991) where a long term utilization of energy stores is required at low activity levels (Pörtner et al., 1996, see below). The comparison of the squid and the digging worm emphasizes that differences in anaerobic metabolic rate cause the differences in slopes (at unchanged linearity) in the octopine/ $\mathrm{pH}$ relationships (Fig. 4). The differences in metabolic rate reflect a delayed depletion of the phosphagen and also less of a decrease in the Gibb's free energy change of ATP hydrolysis in L. brevis and even more so $S$. nudus compared to both I. illecebrosus and L. pealei (Pörtner et al., 1996, Table 2). This relates to a low energy turnover mode of locomotion not only for $L$. brevis, but also for the worm, in accordance with the energy saving strategy discussed above. Anaerobic marathon digging by $S$. nudus in the oxygen deficient marine sediment is associated with an even larger extent of protection of ATP free energy change than in the brief squid (Table 2) suggesting that such a strategy may be typical for hypoxia tolerant animals.

In both the brief squid and the worm, a trend becomes visible to reduce performance at higher levels of ATP free energy change compared to $L$. pealei and I. Illecebrosus (Fig. 6, Table 2). Fatigue or, more adequately, the inability to maintain maximum swimming speeds or digging rates may then no longer be related to the drop in ATP free energy change (Fig. 6) but may mirror the reduction in muscular performance elicited by the combined effects of low $\mathrm{pH}$ and elevated inorganic phosphate levels on muscular performance (cf. Fitts, 1994). Actually, the lower degree of proton buffering in $L$. brevis and $S$. nudus (Fig. 4) means that $\mathrm{pH}$ falls more rapidly in these species and may cause a protective decrease in performance before the energy status reaches a critically low level. A decrease in performance induced by acidosis is typically observed in many types of muscle tissue (Fitts, 1994; Hartmund and Gesser, 1995) and may be protective during ischemia, long term environmental stress or extended periods of anaerobic exercise.

These considerations lead to additional insights for the three squid species and the worm (Table 2). Reduced acidosis (as in L. pealei) poses a higher threat of ATP degradation causing more severe and, possibly, longer lasting symptoms of fatigue at low energy levels. In contrast, a severe acidosis at reduced rates of phosphagen depletion (as in L. brevis or S. nudus) reduces performance and may support the more economical and long term use of anaerobic resources. Maximum anaerobic ATP and phosphagen turnover combined with a high rate of glycolytic proton production (as in I. illecebrosus) use the advantages of acidosis (protection of ATP levels owing to maximum exploitation of the phosphagen) at maximum levels of performance until the critical level of acidosis or energy status may be reached. Again, a comparable analysis for vertebrates of different lifestyles is not available.

As discussed above squid do not release significant amounts of $\mathrm{H}^{+}$and glycolytic end products into the blood. In $S$. nudus the extent to which protons are released into the extracellular fluids depends upon the rate of anaerobic glycolysis. At reduced levels of octopine formation (Pörtner, 1986) more than $90 \%$ of the metabolic protons left the body wall musculature and reached the 
extracellular space. This process would reduce the drop in $\mathrm{pH}_{\mathrm{i}}$, delay the use of the phosphagen and extend the period during which exercise is possible. There appears to be a tradeoff between 'voluntary' low rates of anaerobic exercise which avoid the intracellular acidosis and, thereby, allow for extended exercise periods on the one side and, on the other side, the maximized use of anaerobic resources, possibly in a stress situation, which leads to more severe acidosis, thereby, passively limits muscular performance and 'enforces' a reduction in the use of anaerobic resources.

In conclusion, reducing the energy requirements for locomotion in hypoxic environments protracts the depletion of anaerobic resources and also delays fatigue through a slower use of the phosphagen. Development of an acidosis is almost unchanged, albeit at reduced rates of phosphagen depletion. The acidosis protects the levels and energy contents of the adenylates (Gibb's free energy change of ATP hydrolysis) and may support a reduction of performance prior to fatigue which might be understood as a strategy to extend the period of activity in hypoxic environments. If metabolic expenditure is low to begin with, effective $\mathrm{pH}_{\mathrm{i}}$ regulation may contribute to a long term use of anaerobic resources as seen in $S$. nudus. As a corollary, the capacity of $\mathrm{pH}_{\mathrm{i}}$ regulation strongly modulates the use of anaerobic resources. Progressive acidification first supports maximum levels of activity but then sets a limit to the level of performance and, finally, the period of anaerobic exercise.

\section{Perspectives: tradeoffs between aerobic scope, muscular performance and body size}

It has been concluded above that a species like L. brevis is operating at environmental limits of temperature and oxygen availability. The reliance on oxygen uptake via the skin and maximized use of blood oxygen transport further indicates that in highly active muscular squid like I. illecebrosus, the capacity to extract enough ambient oxygen operates at the limits of ambient oxygen levels. Small body size favours oxygen uptake owing to improved volume to body surface ratios. This may actually be one explanation of why L. brevis remains rather small in a warm environment where its metabolic rate is high, where hypoxia events occur regularly and where at approximately $25^{\circ} \mathrm{C}$ maximum water oxygen levels at air saturation only reach between 60 and $65 \%$ of the levels found at polar $\left(0{ }^{\circ} \mathrm{C}\right)$ or deep sea $\left(2-4{ }^{\circ} \mathrm{C}\right)$ temperatures.

The outline of an oxygen limited performance and the maximized use of ambient oxygen in $I$. illecebrosus suggests that similar conclusions can be drawn for this ommastrephid squid. The high performance levels of this species not just take advantage of the constant environmental conditions of the pelagic, open ocean waters but are only possible under these conditions. Adult individuals of this species are likely to operate at their maximum body size since this size may be the maximum possible which allows to extract significant amounts of oxygen from the water via the skin (Fig. 8).

Following this line of thought the large body size of giant squid may only be possible under the cold temperature conditions of the deep sea, when oxygen solubility is high and metabolic energy requirements are reduced for all species owing to food and temperature constraints. This leaves more room for increasing body size, supported by low SMR, low net metabolic scopes, and, also, energy efficient growth (Pörtner, 2002a,b; cf. Pörtner et al., 2001, Fig. 8). Accordingly, exposure to warm waters may cause asphyxiation and death of these animals, because water oxygen levels fall and oxygen demand rises to levels beyond critical. Restriction of giant squids to cold water environments is also reflected in the observation that the blood pigment is adapted to function at low temperatures only (Brix, 1983). As a corollary, maximum body size in squid appears to be the result of a tradeoff between maximum energy expenditure attainable in a certain environment, available strategies to maximize the use of ambient oxygen and the potential development and use of energy saving strategies without compromising the successful competition with pelagic vertebrates.

In a completely different environment, oxygen availability very likely also limits the body size of the marine worm, S. nudus, which also relies on cutaneous respiration. According to the above, aerobic energy used by ventilatory activity reflects the maximum aerobic scope available to this species, which is larger in small than in large animals. On the one hand a minimized aerobic scope in oxygen poor environments will allow for the development of a larger body size, on the other hand the larger body size will cause oxygen limitations 


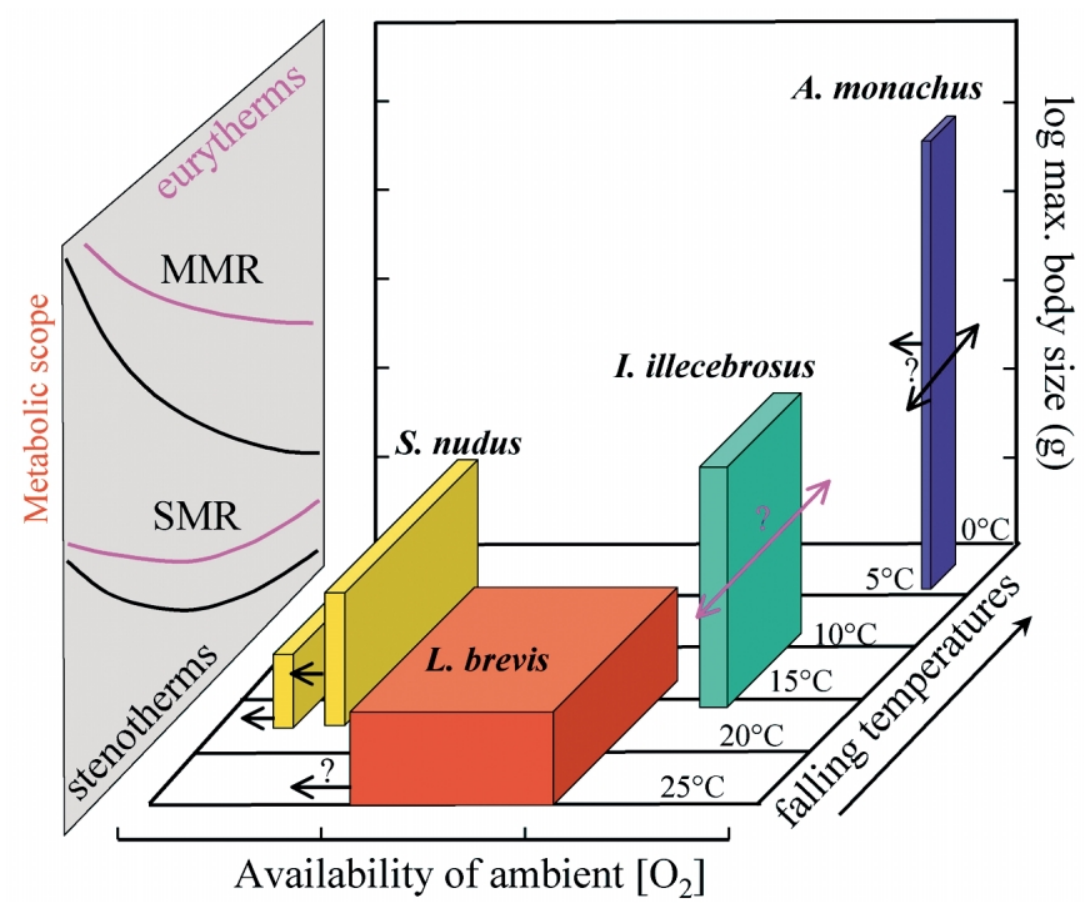

Fig. 8. Modelled, semi-quantitative depiction of the constraints and tradeoffs imposed by constant or fluctuating oxygen availability and temperature, as well as the degree of eurythermality or euryoxia (reflected by the lengths and widths of the respective box for each species), and, in consequence, temperature dependent aerobic scope, on body size in cephalopods and sipunculids (SMR: standard metabolic rate, MMR: maximum metabolic rate, distinguished between polar, i.e. Antarctic and deep sea stenotherms, where no metabolic cold compensation occurs, and cold adapted eurytherms, which display significant metabolic cold adaptation, based on Pörtner et al., 1984b; Pörtner, 2002a,b). Reduced standard metabolism and net metabolic scope in polar and deep sea stenotherms, including the giant squid, combined with increased oxygen solubilities in cold waters are interpreted as preconditions for the development of gigantism in cold waters. In eurythermal squids with maximized aerobic energy turnover in warm water or temperate environments, like I. illecebrosus and L. brevis, or in the sipunculid worms living in hypoxic environments, maximum body size is also interpreted to be set by the combined effects of limited oxygen availability and the degree of temperature fluctuations (for further explanations see text. Arrows and question marks indicate uncertainties in knowledge of the actual level of eurythermality or euryoxia. With respect to euryoxia note that the figure emphasizes ambient oxygen maxima rather than the full range of oxygen, incl. hyperoxia tolerance. It does not reflect that the level of hypoxia tolerance, also indicated by arrows pointing left, will vary with ambient temperature, cf. Pörtner, 2002a. A wide range of ambient oxygen levels is emphasized for L. brevis and suggested to be relevant in reducing maximum body size.).

to become effective already under resting conditions. Depending on whether individuals are found in coarse or fine sandy sediments those found in coarse sands reach 3-5 times larger body sizes. Since the non-permanent burrow has only one opening towards the surface water all ventilatory water is pressed into the sand, a process which finds less resistance in coarse compared to fine sediments. Large animals need to pump a larger volume of water and, therefore, experience this limitation earlier than small animals. Large specimens also maintain lower levels of body fluid $P_{\mathrm{O}_{2}}$ at the same level of ambient oxygen reflecting an increased level of oxygen limitation at large body size (Pörtner et al., 1985) or, in other words, a limitation of body size by oxygen availability.

Body size limitations by oxygen availability have most recently been discussed for amphipods and deep sea gastropods based on correlations between maximum body size within those groups and temperature dependent oxygen content in marine and freshwater environments (Chapelle and Peck, 1999; McClain and Rex, 2001). The present discussion provides some insight into the physiological mechanisms and tradeoffs behind those empirical observations. The model depicted in Fig. 8 suggests that not just the rise in ambient oxygen levels but also the decrease in SMR and net aerobic 
scope at low temperature are most likely preconditions for a cold induced rise in body size.

As a corollary, environmental and lifestyle constraints shape the level of aerobic scope available to the marine invertebrate species discussed. Whereas oxygen limitations in the sediment minimize aerobic scope for exercise and thereby allow for larger body sizes in the worm, aerobic scope is maximized in squid owing to the necessity to compete with vertebrates at similar performance levels. Within their group, the elite athletes have maximized aerobic performance up to the limits set by environmental constraints. In a tradeoff between aerobic scope and body size this may limit body size depending on environmental characteristics. In some species, body size is likely set to a maximum level that does allow maintenance of just sufficient aerobic scope. Similar to aerobic scope, which limits the capacity for long term and long distance cruising at high velocities, the rate of anaerobic performance depends on the maximum energy turnover required for escape or attack in the case of ommastrephid squid or on the length of time when anaerobic metabolism is needed, e.g. during excursions into hypoxic environments linked to food uptake, in the case of L. brevis and the digging worm. It should be very stimulating to test the applicability of these principles in other organisms as well including the group of vertebrates where such detailed analyses of environmental and lifestyle limitations to the capacity of muscular exercise, including the implications for body size, have not yet been carried out.

\section{Acknowledgments}

The author wishes to thank Iris Hardewig for exercising the worms. Supported by grants from the Deutsche Forschungsgemeinschaft (Po 278).

\section{References}

Bone, Q., Pulsford, A., Chubb, A.D., 1981. Squid mantle muscle. J. Mar. Biol. Ass. UK 61, 327-342.

Brett, J.R., 1964. The respiratory metabolism and swimming performance of young sockeye salmon. J. Fish. Res. Bd. Canada 21, 1183-1226.

Bridges, C.R., 1994. Bohr and Root effects in cephalopod haemocyanins-paradox or pressure in Sepia officinalis. In: Pörtner, H.O., O’Dor, R.K., MacMillan, D. (Eds.), Physiology of Cephalopod Molluscs-Lifestyle and Performance Adaptations. Gordon and Breach Publishers, Basel, pp. 121-130.
Brill, R.W., 1996. Selective advantages conferred by the high performance physiology of tunas, billfishes, and dolphin fish. Comp. Biochem. Physiol. 113A, 3-15.

Brix, O., 1983. Giant squids may die when exposed to warm currents. Nature 303, 422-423.

Brix, O., Bårdgard, A., Cau, A., Colosimo, A., Condo, S.G., Giardina, B., 1989. Oxygen binding properties of cephalopod blood with special reference to ambient temperatures and ecological distribution. J. Exp. Zool. 252, 34-42.

Burgetz, I.J., Rojas-Vargas, A., Hinch, S.G., Randall, D.J., 1998. Initial recruitment of anaerobic metabolism during sub-maximal swimming in rainbow trout (Oncorhynchus mykiss). J. Exp. Biol. 201, 2711-2721.

Chapelle, G., Peck, L.S., 1999. Polar gigantism dictated by oxygen availability? Nature 399, 114-115.

Chih, C.P., Elllington, W.R., 1985. Metabolic correlates of intracellular $\mathrm{pH}$ change during rapid contractile activity in a molluscan muscle. J. Exp. Zool. 236, 27-34.

Childress, J.J., Seibel, B.A., 1998. Life at stable low oxygen levels: adaptations of animals to oceanic oxygen minimum layers. J. Exp. Biol. 201, 1223-1232.

Clarke, M.R., Denton, E.J., Gilpin-Brown, J.B., 1979. On the use of ammonium for buoyancy in squids. J. Mar. Biol. Ass. UK 59, 259-276.

Combs, C.A., Ellington, W.R., 1996. Graded intracellular acidosis produces extensive and reversible reductions in the effective free energy change of ATP hydrolysis in a molluscan muscle. J. Comp. Physiol. 165B, 203-212.

Finke, E., Pörtner, H.O., Lee, P.G., Webber, D.M., 1996. Squid life in shallow waters: oxygen limitation of metabolism and performance in exercising gulf squid, Lolliguncula brevis. J. Exp. Biol. 199, 911-921.

Fitts, R.H., 1994. Cellular mechanisms of muscle fatigue. Physiol. Rev. 7, 49-94.

Florkin, M., 1933. Recherches sur les hémérythrines. Arch. Int. Physiol. 36, 247-328.

Goolish, E.M., 1991. Anaerobic swimming metabolism of fish: sit-and-wait versus active forager. Physiol. Zool. 64, 485-501.

Gosline, J.M., Demont, M.E., 1985. Jet-propelled swimming in squids. Sci. Am. 252, 96-103.

Gosline, J.M., Steeves, J.D., Harman, A.D., Demont, M.E., 1983. Patterns of circular and radial muscle activity in respiration and jetting of the squid, Loligo opalescens. J. Exp. Biol. 104, 97-109.

Grieshaber, M., Gäde, G., 1976. The biological role of octopine in the squid, Loligo vulgaris (Lamarck). J. Comp. Physiol. 108, 225-232.

Grieshaber, M.K., Hardewig, I., Kreutzer, U., Pörtner, H.O., 1994. Physiological and metabolic responses to hypoxia in invertebrates. Rev. Physiol. Biochem. Pharmacol. 125, 43-147.

Hardewig, I., Addink, A.D.F., Grieshaber, M.K., Pörtner, H.O., van den Thillart, G., 1991. Metabolic rates at different oxygen levels determined by direct and indirect calorimetry in the oxyconformer Sipunculus nudus. J. Exp. Biol. 157, 143-160.

Hartmund, T., Gesser, H., 1995. Acidosis, glycolysis and energy state in anaerobic heart tissue from rainbow trout. J. Comp. Physiol. 165B, 219-229. 
Hendrickson, W.A., Smith, J.L., Sheriff, S., 1985. Structure and function of hemerythrins. In: Lamy, J., Truchot, J.-P., Gilles, R. (Eds.), Respiratory Pigments in Animals. Springer, Berlin, pp. 1-8.

Hoar, J., Sim, E., Webber, D.M., O’Dor, R.K., 1994. The role of fins in the competition between squid and fish. In: Rayner, J., Bone, Q., Maddock, L. (Eds.), Mechanics and Physiology of Animal Swimming. Cambridge University Press, UK, pp. 27-43.

Hochachka, P.W., 1994. Oxygen efficient design of cephalopod muscle. In: Pörtner, H.O., O’Dor, R.K., MacMillan, D. (Eds.), Physiology of Cephalopod Molluscs-Lifestyle and Performance Adaptations. Gordon and Breach Publishers, Basel, pp. 61-67.

Hochachka, P.W., Mommsen, T.P., 1983. Protons and anaerobiosis. Science 219, 1391-1398.

Kammermeier, H., Schmidt, P., Jungling, E., 1982. Free energy change of ATP-hydrolysis: a causal factor of early hypoxic failure of the myocardium? J. Mol. Cell. Cardiol. 14, 267-277.

Kemper, W.F., Lindstedt, S.L., Hartzler, L.K., Hicks, J.W., Conley, K.E., 2001. Shaking up glycolysis: sustained, high lactate flux during aerobic rattling. Proc. Natl. Acad. Sci. 98, 723-728.

Kieffer, J.D., 2000. Limits to exhaustive exercise in fish. Comp. Biochem. Physiol. 126A, 161-179.

Korsmeyer, K.E., Dewar, H., Lai, N.C., Graham, J.B., 1996. The aerobic capacity of tunas: adaptation for multiple metabolic demand. Comp. Biochem. Physiol. 113A, 17-24.

Lucas, M.C., Johnstone, A.D.F., Tang, J., 1993. An annular respirometer for measuring aerobic metabolic rates of large, schooling fish. J. Exp. Biol. 175, 325-331.

Lykkeboe, G., Brix, O., Johansen, K., 1980. Oxygen-linked $\mathrm{CO}_{2}$ binding independent of $\mathrm{pH}$ in cephalopod blood. Nature 287, 330-331.

Mangum, C.P., 1990. Gas transport in the blood. In: Gilbert, D.L., Adelman, W.J., Arnold, J.M. (Eds.), Squid as Experimental Animals. Plenum Press, New York, pp. 443-468.

Manwell, C., 1960. Histological specificity of respiratory pigments. II. Oxygen transfer systems involving hemerythrins in sipunculid worms of different ecologies. Comp. Biochem. Physiol. 1, 277-285.

McClain, C.R., Rex, M.A., 2001. The relationship between dissolved oxygen concentration and maximum size in deepsea turrid gastropods: an application of quantile regression. Mar. Biol. 139, 681-685.

Miller, K.I., 1994. Cephalopod haemocyanins. A review of structure and function. In: Pörtner, H.O., O'Dor, R.K., MacMillan, D. (Eds.), Physiology of Cephalopod Molluscs-Lifestyle and Performance Adaptations. Gordon and Breach Publishers, Basel, pp. 101-120.

Milligan, C.L., 1996. Metabolic recovery from exhaustive exercise in rainbow trout. Comp. Biochem. Physiol. 113A, 51-60.

Mommsen, T.P., Ballantyne, J., MacDonald, D., Gosline, J., Hochachka, P.W., 1981. Analogues of red and white muscle in squid mantle. Proc. Natl. Acad. Sci. USA 78, 3274-3278.

O’Dor, R.K., Webber, D.M., 1986. The constraints on cephalopods: why squid aren't fish. Can. J. Zool. 64, 1591-1605.

O’Dor, R.K., Webber, D.M., 1991. Invertebrate athletes: tradeoffs between transport efficiency and power density in cephalopod evolution. J. Exp. Biol. 160, 93-112.
O’Dor, R.K., Pörtner, H.O., Shadwick, R.E., 1990. Squid as elite athletes: locomotory, respiratory and circulatory integration. In: Gilbert, D.L., Adelman, W.J., Arnold, J.M. (Eds.), Squid as Experimental Animals. Plenum Press, New York, pp. 481-503.

O’Dor, R.K., Hoar, J.A., Webber, D.M., et al., 1994. Squid (Loligo forbesi) performance and metabolic rates in nature. In: Pörtner, H.O., O’Dor, R.K., MacMillan, D. (Eds.), Physiology of Cephalopod Molluscs-Lifestyle and Performance Adaptations. Gordon and Breach Publishers, Basel, pp. 163-177.

Pörtner, H.O., 1986. Proton balance of anaerobic and postanaerobic metabolism- interrelations with $\mathrm{pH}$ regulation in marine invertebrates. Zool. Beitr. N.F. 30, 231-247.

Pörtner, H.O., 1987. Contributions of anaerobic metabolism to $\mathrm{pH}$ regulation in animal tissues: theory. J. Exp. Biol. 131, 69-87.

Pörtner, H.O., 1990a. An analysis of the effects of $\mathrm{pH}$ on oxygen binding by squid (Illex illecebrosus, Loligo pealei) haemocyanin. J. Exp. Biol. 150, 407-424.

Pörtner, H.O., 1990b. Determination of intracellular buffer values after metabolic inhibition by fluoride and nitrilotriacetic acid. Respir. Physiol. 81, 275-288.

Pörtner, H.O., 1993. Multicompartmental analyses of acidbase and metabolic homeostasis during anaerobiosis: invertebrate and lower vertebrate examples. In: Hochachka, P.W., Lutz, P.L., Sick, T., Rosenthal, M., van den Thillart, G. (Eds.), Surviving Hypoxia: Mechanisms of Control and Adaptation. CRC Press Inc, Boca Raton, pp. 139-156.

Pörtner, H.O., 1994. Coordination of metabolism, acid-base regulation and haemocyanin function in cephalopods. In: Pörtner, H.O., O’Dor, R.K., MacMillan, D. (Eds.), Physiology of Cephalopod Molluscs-Lifestyle and Performance Adaptations. Gordon and Breach Publishers, Basel, pp. 131-148.

Pörtner, H.O., 2001. Climate change and temperature dependent biogeography: oxygen limitation of thermal tolerance in animals. Naturwissenschaften 88, 137-146.

Pörtner, H.O., 2002a. Climate variations and the physiological basis of temperature dependent biogeography: systemic to molecular hierarchies of thermal tolerance in animals. Comp. Biochem. Physiol. 132A, 739-761.

Pörtner, H.O., 2002b. Physiological basis of temperature dependent biogeography: tradeoffs in muscle design and performance in polar ectotherms. J. Exp. Biol. 205, 2217-2230.

Pörtner, H.O., Heisler, N., Grieshaber, M.K., 1984a. Anaerobiosis and acid-base status in marine invertebrates: a theoretical analysis of proton generation by anaerobic metabolism. J. Comp. Physiol. 155B, 1-12.

Pörtner, H.O., Kreutzer, U., Siegmund, B., Heisler, N., Grieshaber, M.K., 1984b. Metabolic adaptation of the intertidal worm Sipunculus nudus to functional and environmental hypoxia. Mar. Biol. 79, 237-247.

Pörtner, H.O., Heisler, N., Grieshaber, M.K., 1985. Oxygen consumption and mode of energy production in the intertidal worm Sipunculus nudus L.: definition and characterization of the critical $P_{\mathrm{O}_{2}}$ for an oxyconformer. Respir. Physiol. 59, 361-377.

Pörtner, H.O., Boutilier, R.G., Tang, Y., Toews, D.P., 1990. Determination of intracellular $\mathrm{pH}$ and $\mathrm{P}_{\mathrm{CO}_{2}}$ after metabolic inhibition by fluoride and nitrilotriacetic acid. Respir. Physiol. 81, 255-274. 
Pörtner, H.O., Webber, D.M., Boutilier, R.G., O’Dor, R.K., 1991. Acid-base regulation in exercising squid (Illex illecebrosus, Loligo pealei). Am. J. Physiol. 261, R239-R246.

Pörtner, H.O., Webber, D.M., O'Dor, R.K., Boutilier, R.G., 1993. Metabolism and energetics in squid (Illex illecebrosus, Loligo pealei) during muscular fatigue and recovery. Am. J. Physiol. 265, R157-R165.

Pörtner, H.O., Grieshaber, M.K., 1993. Characteristics of the critical $P_{\mathrm{O}_{2}}(\mathrm{~s})$ : gas exchange, metabolic rate and the mode of energy production. In: Bicudo, J.E.P.W. (Ed.), The Vertebrate Gas Transport Cascade: Adaptations to Environment and Mode of Life. CRC Press Inc, Boca Raton FL, USA, pp. 330-357.

Pörtner, H.O., Finke, E., Lee, P.G., 1996. Effective Gibb's free energy change of ATP hydrolysis and metabolic correlates of intracellular $\mathrm{pH}$ in progressive fatigue of squid (Lolliguncula brevis) mantle muscle. Am. J. Physiol. 271, R1403-R1414.

Pörtner, H.O., Hardewig, I., Sartoris, F.J., van Dijk, P., 1998. Energetic aspects of cold adaptation: critical temperatures in metabolic, ionic and acid-base regulation? In: Pörtner, H.O., Playle, R. (Eds.), Cold Ocean Physiology. Cambridge University Press, pp. 88-120.

Pörtner, H.O., Zielinski, S., 1998. Environmental constraints and the physiology of performance in squids. In: Payne, A.I.L., Lipinski, M.R., Clarke, M.R., Roeleveld, M.A.C. (Eds.), Cephalopod Biodiversity Ecology and Evolution. S. Afr. J. Mar. Sci. 20, 207-221.

Pörtner, H.O., Berdal, B., Blust, R., et al., 2001. Climate effects on growth performance, fecundity and recruitment in marine fish: developing a hypothesis for cause and effect relationships in Atlantic cod (Gadus morhua) and common eelpout (Zoarces viviparus). Continental Shelf Research 21, 1975-1997.

Shadwick, R.E., 1994. Mechanical organization of the mantle and circulatory system of cephalopods. In: Pörtner, H.O.,
O’Dor, R.K., MacMillan, D. (Eds.), Physiology of Cephalopod Molluscs-Lifestyle and Performance Adaptations. Gordon and Breach Publishers, Basel, pp. 69-85.

Trueman, E.R., Foster-Smith, R.L., 1976. The mechanism of burrowing of Sipunculus nudus. J. Zool. 179, 373-386.

Vecchione, M., 1991. Dissolved oxygen and the distribution of the euryhaline squid Lolliguncula brevis. Abstract Bull. Mar. Sci. 49, 668-669.

Voight, J.R., Pörtner, H.O., O'Dor, R.K., 1994. A review of ammonia-mediated buoyancy in squids (Cephalopoda: Teuthoidea). In: Pörtner, H.O., O'Dor, R.K., MacMillan, D. (Eds.), Physiology of Cephalopod Molluscs-Lifestyle and Performance Adaptations. Gordon and Breach Publishers, Basel, pp. 193-203.

Webb, P.W., 1971. The swimming energetics of trout. II. Oxygen consumption and swimming efficiency. J. Exp. Biol. 55, 521-540.

Webber, D.M., O'Dor, R.K., 1985. Monitoring the metabolic rate and activity of free-swimming squid with telemetered jet pressure. J. Exp. Biol. 126, 205-224.

Webber, D.M., Aitken, J.P., O’Dor, R.K., 2000. Costs of locomotion and vertic dynamics of cephalopods and fish. Physiol. Biochem. Zool. 73, 651-662.

Wells, M.J., 1994. The evolution of a racing snail. In: Pörtner, H.O., O’Dor, R.K., MacMillan, D. (Eds.), Physiology of Cephalopod Molluscs-Lifestyle and Performance Adaptations. Gordon and Breach Publishers, Basel, pp. 1-12.

Wells, M.J., Hanlon, R.T., Lee, P.G., Dimarco, F.P., 1988. Respiratory and cardiac performance in Lolliguncula brevis (Cephalopoda, Myopsida): the effects of activity, temperature and hypoxia. J. Exp. Biol. 138, 17-36.

Wieser, W., 1986. Bioenergetik. Energietransformationen bei Organismen. Georg Thieme, Stuttgart.

Zielinski, S., Lee, P.G., Pörtner, H.O., 2000. Metabolic performance of the squid Lolliguncula brevis during hypoxia: an analysis of the critical $P_{\mathrm{O}_{2}}$. J. Exp. Mar. Biol. Ecol. 243, 241-259. 